\title{
Research on the Influence of Population Aging on Labor Cost in Hebei Province
}

\author{
Shixin $\mathrm{Huo}^{1 *}$ \\ ${ }^{1}$ Beijing Jiaotong University Beijing, China
}

\begin{abstract}
Background. In the 1970s and 1980s, China implemented the family planning policy, which increased the proportion of the working age population by controlling the population fertility rate, bringing a demographic dividend to China at that time. Because of the implementation of family planning policy, China has stepped into an aging society in advance. The aging of population has a profound impact on all aspects of society. This paper has a strong practical significance for the study of the impact of aging of population on labor cost. Methods. Based on the theories of population transformation, population dividend and market supply-demand equilibrium, this paper uses the methods of literature review and statistical analysis to look up the relevant data of Hebei Provincial Bureau of statistics and National Bureau of statistics, and uses Stata16 to analyze the correlation and significance test between the elderly population coefficient and labor cost. Finally, it analyzes the relationship between the aging population and labor supply and demand the influence path is discussed. Results. The results show that there is a significant positive correlation between the elderly population coefficient and labor cost. Conclusion. The aging of population structure makes the supply of young and middle-aged labor insufficient. At the same time, due to the strong demand of the old industry, the demand for labor increases. The imbalance of supply and demand leads to the increase of labor cost. The aging of the population indirectly increases the number of years of education for the labor force, the increase of the labor force's investment in its own human capital and the gradual improvement of the current social security system, which also increases the labor cost from the side.
\end{abstract}

\section{Introduction}

In today's world, the problem of population aging is becoming increasingly prominent and has been widely concerned by countries around the world. According to the statistics released by the National Bureau of statistics and the population division of the Department of economic and social affairs of the United Nations, as of July 2018, the total number of China's elderly population (60 years old and above) is 249 million, the world's elderly population (60 years old and above) is about 962 million , and China's elderly population accounts for $25.88 \%$ of the world's elderly population, that is to say, every four elderly people in the world One of them is Chinese. At the same time, according to the old standard (the population over 60 years old is the aging population), by 2018, China's population aging rate is $17.9 \%$, far exceeding the United Nations standard of $10 \%$. Hebei Province has 14.9615 million people aged 60 and above, accounting for $19.80 \%$ of the total population, with a higher degree of aging .

The aging of population is an inevitable and coming problem in China's social development. To explore the influence path of aging of population on labor cost and grasp the law of population structure change on labor cost can serve as a theoretical guide for us to propose ways to reduce the negative impact of aging of population on
Hebei Province and even China's economy, and change the core competitiveness of relevant enterprises It is of great significance to social development.

\subsection{Population aging reduces economic growth potential}

On the basis of previous studies, Ki Hong choiand sungwheeshin [4] has improved the accumulation of human capital and individual utility function, developed a new overlapping generation model, which can be used for calculation. The final result shows that the aging population seriously reduces the potential of economic growth, so it is necessary to continuously strengthen and improve the quality and quality of labor force Accumulation effect[4]. Bloom,D.E. and D.Canning considered that the population of the middle-aged and the elderly is too high in the process of population aging, resulting in the shortage of the working age population. For a country or region that relies on the input of labor quantity for economic growth, the shortage of labor quantity will become an important factor affecting economic growth[5]. 


\subsection{Aging and demographic dividend}

Geng Zhixiang and sun Qixiang analyzed the impact of delayed retirement on saving rate, capital accumulation, output and other variables by building an extended generation overlapping general equilibrium model. The conclusion is that the response of the public to the increase of life expectancy will increase the saving rate and capital accumulation, and then generate the second demographic dividend [9]. Zhou Hao and Liu Ping believe that the acceleration of the decline of the actual supply of labor will lead to the rise of labor cost, weaken the cost advantage of manufacturing products, and affect the improvement of enterprise competitiveness. Expanding employment, improving the quality of labor and developing the aged labor resources are the best choices to delay the demographic dividend and mitigate the impact [10]. At present, scholars at home and abroad mainly focus on the macro impact of population structure changes caused by aging on industrial upgrading, human capital and economic growth, but rarely focus on the intermediate influencing factor of labor cost.

\section{Methods}

\subsection{Data}

The data are taken from the Economic Yearbook of Hebei Provincial Bureau of Statistics website over the years, and the data related to population data and salary level from 2000 to 2016 are used.

The aging level of population (aging population coefficient) $=$ population aged 65 and above $/$ total population * $100 \%$ labor cost. If referring to the definition of International Labor Organization (ILO) in this paper, there are more than ten components, which are complex, and the proportion of vocational training cost, welfare service cost and other parts is very small, so it is difficult to measure and find relevant data. Therefore, the labor force studied in this paper Cost uses the concept of labor remuneration as a reference. The calculation formula is as follows:

labor remuneration $=$ wage + social security payment $=$ wage + (endowment insurance + medical insurance + industrial injury insurance + unemployment insurance + maternity insurance).

The statistical range of the average wage in Hebei Province before 2009 does not include private enterprises and individual industrial and commercial households. Therefore, the wage here refers to the average wage of Urban Non private units. Later, we will use the standard of "wage $=$ (average wage of Urban Non private sector employees + average wage of urban private sector employees) / 2" to analyze the data in 2009-2017 separately.

According to the state regulations, the minimum base of endowment insurance paid by enterprise employees shall not be less than $60 \%$ of the average social wage. Because the proportion of enterprises to bear all kinds of insurance in Hebei Province is different, but the difference is not big, so take the average value of 11 cities in Hebei
Province, and calculate that the proportion of each unit to bear endowment insurance, medical insurance, unemployment insurance, work-related injury insurance and maternity insurance is about $20 \%, 7 \%, 0.7 \%, 1 \%$ and $0.5 \%$.

The payment formula is as follows: enterprises should pay insurance $=$ payment base $* 60 \% *$ payment proportion of corresponding insurance categories $=$

(Average salary of employees in the previous year / $12 *$ $60 \% *$ payment proportion of corresponding insurance categories.

On the basis of the above calculation formula, by querying the relevant data of Hebei Economic Yearbook, national economic and social development statistical bulletin published on the official website of Hebei Provincial Bureau of statistics and average wage of urban employees in 2017, the results are calculated.

\subsection{Procedure}

The correlation analysis and significance test between the aging population coefficient and labor cost are carried out.

\section{Results}

\subsection{From 2001 to 2017, only the average wage of Urban Non private sector employees was considered in the labor remuneration}

Using Stata16 to make the lattice diagram of the elderly population coefficient and labor remuneration and add the fitting curve as shown in Fig.1, the results show that the elderly population coefficient is positively correlated with labor remuneration.

Test the correlation coefficient of the two, and the results are shown in TABLE I. The matrix shows the correlation between the elderly population coefficient and labor remuneration. The correlation coefficient between the old population coefficient (old100) and the labor remuneration (LC) is 0.9085 , which is significant at the significance level of 0.01 . Therefore, it is considered that there is a strong positive correlation between the old population coefficient and the labor remuneration.

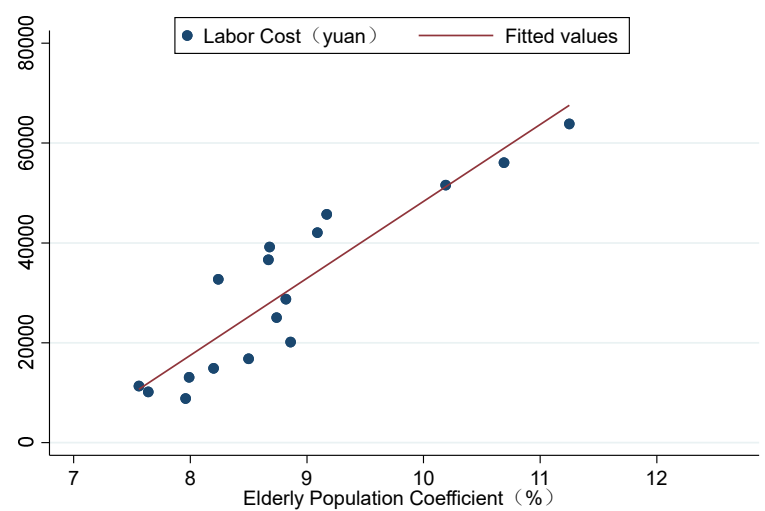

Fig 1. matrix graph and linear fitting curve of elderly population coefficient $(\%)$ 
Table I. correlation analysis

\begin{tabular}{|l|c|c|}
\hline \multicolumn{1}{|c|}{ Variables } & lc & old100 \\
\hline lc & 1.0000 & \\
\hline old100 & $0.9085^{*}$ & 1.0000 \\
\hline p-value & 0.0000 & \\
\hline
\end{tabular}

Try to use linear function model and logarithmic function model for regression, the goodness of fit is 0.8254 and 0.8356 respectively, so choose logarithmic model for regression. Let the old age population coefficient be $\mathrm{x}$, the labor reward be y, and use the curve (1):

$$
y=a+b \ln x
$$

Through fitting analysis, the regression results are shown in TABLE II:

As shown in the TABLE II, LNO represents the logarithm of the elderly population coefficient (\%), LC represents labor remuneration, and the goodness of fit is 0.8356 , indicating that the degree of fit is good, which is significant at the significance level of 0.01 . So we can get the regression equation (2):

$$
y=143374.8 \ln x-281169.8
$$

From the shape of the formula, the labor remuneration will increase with the increase of the elderly population coefficient (\%), and the growth rate will gradually slow down.

Table II. regression analysis of the logarithm of labor

\begin{tabular}{|c|c|c|c|c|c|c|}
\hline Source & ss & df & MS & Number of obs & $=$ & \\
\hline Model & $4.0260 \mathrm{e}+09$ & 1 & $4.0260 \mathrm{e}+09$ & Prob $>F$ & $=$ & 0.000 \\
\hline Residual & 791818302 & 15 & 52787886.8 & R-squared & $=$ & 0.835 \\
\hline Total & $4.8178 e+09$ & 16 & 301111694 & Root MSE & $=$ & 726 \\
\hline
\end{tabular}
remuneration to the elderly population coefficient

\begin{tabular}{r|rrrrrr}
\hline lc & Coef. & Std. Err. & $\mathrm{t}$ & $\mathrm{P}>|\mathrm{t}|$ & [958 Conf. Interval \\
\hline lno & 143374.8 & 16417.42 & 8.73 & 0.000 & 108381.9 & 178367. \\
- cons & -281169.8 & 35721.1 & -7.87 & 0.000 & -357307.6 & -205032. \\
\hline
\end{tabular}

\subsection{Correlation analysis of average wages of urban private institutions in 2009-2017}

Labor remuneration $=$ wage + social security payment $=$ (average wage of Urban Non private employees + average wage of urban private employees) / $2+$ social security payment.

In the same way as the above analysis method, make a lattice diagram of labor remuneration and the elderly population coefficient, as shown in Fig.2, which shows a positive correlation between the two; conduct correlation analysis and test, as shown in TABLE III, the correlation coefficient of the two is 0.9224 , P value is 0.0004 , which shows the two are significant at the significance level of 0.01 .

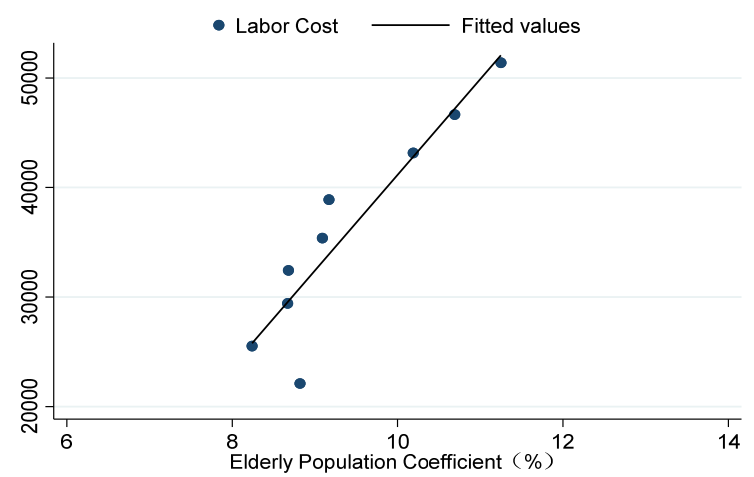

Fig 2. matrix diagram of elderly population coefficient (\%) and labor remuneration

Table III. correlation analysis

\begin{tabular}{|l|c|c|}
\hline \multicolumn{1}{|c|}{ Variables } & alc & old100 \\
\hline alc & 1.0000 & \\
\hline old100 & $0.9224^{*}$ & 1.0000 \\
\hline p-value & 0.0000 & \\
\hline
\end{tabular}

The linear model and the logarithmic model are used for regression, and the goodness of fit is 0.8508 and 0.8546 respectively. The logarithmic function model is used for regression, and the regression results are shown in TABLE IV:

Table IV. regression analysis of the logarithm of labor

\begin{tabular}{|c|c|c|c|c|c|c|c|}
\hline Source & ss & df & MS & \multirow{2}{*}{\multicolumn{2}{|c|}{$\begin{array}{l}\text { Number of obs } \\
\mathrm{F}(1,7) \\
\text { Prob }>\mathrm{F}\end{array}$}} & $=$ & \multirow{2}{*}{$\begin{array}{r}9 \\
41.15 \\
0.0004\end{array}$} \\
\hline Mode1 & 657502157 & 1 & 657502157 & & & $=$ & \\
\hline Residual & 111834741 & 7 & 15976391.6 & & 1ared & $=$ & 0.8546 \\
\hline Total & 769336899 & 8 & 96167112.3 & & MSE & $=$ & 3997 \\
\hline alc & Coef. & Std. Err. & $t$ & $P>|t|$ & [95: C & Conf. & Interva 1] \\
\hline 1 no & 84869.81 & 13229.52 & 6.42 & 0.000 & 53586 & & 116152.6 \\
\hline cons & -153821.1 & 29636.31 & -5.19 & 0.001 & -223899 & & -83742.39 \\
\hline
\end{tabular}
remuneration to the elderly population coefficient

As shown in the TABLE IV, LNO represents the logarithm of the elderly population coefficient (\%), and ALC represents the labor remuneration calculated into the wages of employees in urban private units. The goodness of fit is 0.8546 , indicating that the degree of fit is good, which is significant at the significance level of 0.01 . So, we can get the regression equation (3):

$$
y=84869.81 \ln x-153821.1
$$

From the formula shape, the labor remuneration will increase with the increase of the elderly population coefficient (\%), and the growth rate will gradually slow down.

To sum up, regardless of whether the average wage of urban private sector employees is taken into account, there is a significant positive correlation between labor cost and population aging rate. 


\section{Discussion}

\subsection{Population aging increases labor cost by reducing labor supply}

The theory of population transformation tells us that with the development of economy and society, the whole social population structure will inevitably change to the development mode of low fertility rate, low mortality rate and low natural growth rate. At the same time, the aging population will inevitably affect the labor supply of the whole society.

China's family planning policy in 1970s and 1980s has opened a window of population opportunities, and the country has achieved economic growth by developing labor-intensive industries. At the same time, one of the problems that can not be ignored is the insufficient supply of labor force brought about by the family planning policy 40 years later. At this time, China's early transition to an aging society in the situation of insufficient economic development level presents a state of economic development of "old before rich" [12].

The aging of population not only affects the quantity of labor supply, but also affects the quality of labor supply. On the basis of rational people and complete vision, because human capital investment is the rediscount of future total income level, young people will be more inclined to extend their education years and receive more vocational training to invest in human capital to adapt to market competition. Therefore, the aging population will improve the quality of labor supply.

\subsection{Population aging increases labor cost by increasing labor demand}

The current pension model in China is basically the "241" model, that is, the husband and wife support four elderly people and one child together. In reality, most of the ways of providing for the aged are family based, which requires the family to meet more needs of the elderly. With the deepening of the aging population, the aging population is gradually increasing, and the silver industry has great potential and rapid development.

On the one hand, the increase of the elderly will inevitably increase the social demand for medical care, health care, health care and other aspects; on the other hand, with the social development and improvement of living standards, the consumption concept of the elderly is also changing. The consumption of the elderly is no longer limited to medical and health care, and the demand for the elderly in various industries such as entertainment, tourism, insurance, fitness, home economics is also increasing, which to a certain extent increases the demand of the whole society for labor[14]

\section{Conclusion}

The aging of the population makes a large number of labor force in the dividend period transfer to the elderly population today. In addition to the low fertility rate, the labor supply and reserve resources are relatively insufficient, and the social dependency ratio is improved. At the same time, the deepening of population aging is accompanied by the aging of the labor force - the older labor force grasps production experience and technology, which makes the 15-24-year-old labor force more inclined to choose to continue to receive education. This kind of investment in human capital will also increase the cost of labor employment in the future.

With the development of society and the gradual deepening of the aging process, the social consumption structure and preferences have changed, and the number of consumption of the elderly population in their material and spiritual life is increasing, which leads to the strong demand for the elderly industry in the whole society, indirectly stimulating the production link, and increasing the demand for labor force in the society. The imbalance of supply and demand in the labor market makes the labor cost increase. The increase of its investment in human capital and the gradual improvement of the current social security system also increase the labor cost from the side.

The first possible strategy is to promote the transformation and upgrading of labor-intensive industries through differentiated policies. Although the increase of labor cost reduces the profits of enterprises to a certain extent and forces enterprises to transform and upgrade, the impact of the natural growth of labor cost on enterprises to actively seek transformation and upgrading is not obvious at this stage. Therefore, it is necessary for the government to implement the differentiation policy, incline the technology-oriented industry, and give preferential policies to the labor-intensive enterprises that actively seek transformation.

The second possible strategy is to fully tap the labor resources of the elderly. Hebei Province has a large number of elderly populations, if ignored, it will cause a lot of waste of labor resources. Although a large part of the elderly is in retirement, they are still young and strong, with labor ability and rich work experience. If this part of the elderly can be reemployed, it will not only alleviate the shortage of labor market supply to a certain extent, but also enrich the elderly life of this part of the population. However, there are few jobs for the elderly, which requires the government and enterprises to actively carry out appropriate projects to provide special jobs for the elderly, so that they can return to the labor market.

\section{Acknowledgment}

I would like to thank those who have helped me in my thesis writing, especially Professor Cheng who has provided me with detailed writing advice, which has benefited me a lot.

\section{References}

1. Li Shuang, Tan Yongsheng \& Feng Jie.(2009). Investigation report on the implementation impact of Guangdong Provincial Labor Contract Law, Macroeconomic Research (01),36-42.

2. Du Yang \& Qu Xiaobo.(2010). Labor Contract Law and Firm Labor Cost -- Based on the Investigation and 
Analysis of Export-oriented Manufacturing Enterprises in the Pearl River Delta.Shandong Economy (03),46-51.

3. Wang Yunduo.(2014). Prediction of the impact of population aging on labor supply, human capital and output, Population and Economy (03),69-75.

4. Ki-Hong Choi \& Sungwhee Shin.(2015).Population aging, economic growth, and the social transmission of human capital: An analysis with an overlapping generations model. Economic Modelling(), doi:10.1016/j.econmod.2015.05.015.

5. Bloom, D., Canning, D., \& Sevilla, J. (2003). The demographic dividend: A new perspective on the economic consequences of population change. Rand Corporation.

6. Lu J, Liu L \& Guo ZY.(2018). The impact mechanism of population aging on industrial structure in China: An empirical analysis based on synergistic effect and mediating effect, Chinese Journal of Population Science (03), 15-25+126.

7. Feng Yongqi \& Zhang Junyan.(2018). Review of China's Labor Cost Research, Population Journal (04),103-112.

8. Cai, Fang \& Du, Yang.(2016). Actively Responding to the Rapid Rising of Unit Labor Cost in China's Manufacturing Industry.Front (05), 24 and 25.

9. Geng, Z.X. \& Sun, Q.X. (2017). Population Aging, Delay Retirement and Second Demographic Dividend, Financial Research (01),52-68.

10. Zhou H \& Liu P. (2016). The impact of population aging on labor supply and labor productivity in China, Journal of Theoretical Studies (03),106-110.

11. Chen Wei, Huang Xiaoyan." A Review on the Theory of Population Transition." Chinese Population Science.05(1999)

12. Cai, Fang \& Wang, Meiyan.(2006). "Aging before Rich" and Labor Shortage, Open Review (01),31-39.

13. Yu Zhentao \& Hua Shuang.(2016). The Impact of Ageing Economy on Chongqing Economy and Industrial Policy, Market Modernization (19),157158. 